Abstract 479 Table 2 Comparison with published haematological toxicity data for cancer chemoradiotherapy with IMRT/VMAT

\begin{tabular}{|l|l|l|l|l}
\hline Parameter & Reported \% & $\begin{array}{l}\text { Comparator } \\
\text { value }\end{array}$ & UCLH \% & P value \\
\hline Grade 3 or more neutropenia & $2.7-19.2^{\%}{ }^{3-12}$ & $10 \%$ & & \\
\hline $\begin{array}{l}\text { Grade } 2 \text { or more } \\
\text { thrombocytopenia }\end{array}$ & $2.7-11.2^{3-11}$ & $8 \%$ & $33.3 \%$ & 0.000 \\
\hline Grade 3 or more lymphopenia & $22.5 \%^{13}$ & $22.5 \%$ & $96.3 \%$ & 0.000 \\
\hline
\end{tabular}

radiation. Maximum haematological toxicity observed is given in table 1.

Two had received less than 5 cycles of cisplatin due to thrombocytopenia, while 2 others for non-haematological toxicity. 3 others have managed 5 cycles with G CSF support

Table 2 gives a comparison with published haematological toxicity data for cervical cancer IMRT/VMAT.

Grade 4 lymphopenia was significantly associated with having extended field radiotherapy $(\mathrm{p}=0.029)$ and Grade 3 or more thrombocytopenia with induction chemotherapy $(p=0.021)$. No associations could be elicited with stage $111 \mathrm{c}$ or higher disease, having lymph node boost or dose more than $50.4 \mathrm{~Gy}$.

Conclusion Significantly worse Thrombocytopenia and lymphopenia was seen compared to published data. However, there is heterogeneity in patient populations and treatments within existing studies with little data on the effects of extended field radiotherapy, lymphnode boosts or induction chemotherapy. We are therefore conducting a dosimetric analysis to investigate if bone marrow sparing VMAT could reduce the toxicity in this population of patients.

Disclosures None.

\section{INCIDENCE OF SEXUAL DYSFUNCTION AMONG CERVICAL CANCER PATIENTS IN A TERTIARY MEDICAL CENTER TREATED WITH CHEMORADIATION FROM JUNE TO DECEMBER 2019}

Thalia Tubungbanua, Helen Amorin. Vicente Sotto Memorial Medical Center; Obstetrics and Gynecology

\subsection{6/ijgc-2020-ESGO.39}

Introduction/Background Gynecologic cancers greatly affect a woman's sexuality, sexual functioning, intimate relationships, and sense of self. Twenty-three to seventy percent of cervical cancer survivors report problems with their sexual functioning. However, little is known about how sexual dysfunction affect their quality of life since many of them report psychosexual healthcare needs, but only one-third seek professional help. Evaluating their female sexual function will help identify the presence of sexual dysfunction among cervical cancer survivors, provide appropriate intervention and improve their quality of life.

Methodology The study used a prospective, cross-sectional survey design that employed a self-administered questionnaire using the Female Sexual Function Index (FSFI) to identify the presence of sexual dysfunction among cervical cancer patients in a tertiary medical center from June to December 2019. Descriptive statistics were reported to describe the distribution of patients in terms of the different numerical variables, whereas frequency and simple percentage were used to determine the distribution of respondents in terms of the different categorical variables.

Results Forty-two cervical cancer patients were assessed. The mean age of the studied population was 44.85. More than half was married (59.52\%), and majority was from Cebu City (66.78\%). Approximately 43\% (42.86\%) finished college and were mostly catholics (69.05\%). The mean age of diagnosis was 42.85 , with an average gravidity and parity of 1 . Most of the patients interviewed were diagnosed with stage $3 \mathrm{~B}$ cervical cancer (42.86\%). The mean overall Female Sexual Function Index (FSFI) score of the studied population was 6.59, which indicated that all of the patients studied had female sexual dysfunction.

Conclusion All the cervical cancer patients included in this study had female sexual dysfunction as evidenced by the low FSFI scores in each of the 6 dimensions and low overall FSFI score.

Disclosures None.

\section{LOCAL AND SYSTEMIC CHANGES ASSOCIATED WITH THE INNATE IMMUNE RESPONSE AND IMMUNOREGULATORY MECHANISMS RESPONSIBLE FOR THE ESTABLISHMENT AND PROGRESSION OF INVASIVE CERVICAL CARCINOMA}

${ }^{1}$ Olga Kurmyshkina, ${ }^{2}$ Pavel Kovchur, ${ }^{3}$ Tatyana Volkova. ${ }^{1}$ Petrozavodsk State University; Institute of Medicine; Department of Human and Animal Physiology, Pathophysiology, Histology; ${ }^{2}$ Petrozavodsk State University; Institute of Medicine; ${ }^{3}$ Petrozavodsk State University; Institute of High-Tech Biomedicine

\subsection{6/ijgc-2020-ESG0.40}

Introduction/Background The mechanisms of innate immune response and the immune checkpoint (IC) system-governed mechanisms are the two interconnected areas currently becoming the focus of world research in view of the prospects for therapeutic reactivation of antitumor immunity. This may be especially relevant to virus-associated cancers (as, for example, most cases of cervical cancer), which are known to develop as a result of persistent infection, long-term antigen exposure and are frequently characterized by chronically inflamed environment and local and/or systemic immunosuppression. Studying the immune changes that accompany the earliest stages of tumor progression may provide insight into the mechanisms driving the onset of metastasis; and, in this respect, systemic changes observed in peripheral blood (PB) may possibly reflect local dysfunctions at the tumor site. In case of cervical cancer, these assumptions need more extensive research evidence.

Methodology To characterize the changes in the local microenvironment, we compared the transcriptomes of the early invasive squamous cell cervical cancer and its precursor high-grade 
lesions by performing RNA-sequencing and bioinformatics analysis on a panel of 12 fresh tissue samples comprising $\mathrm{HPV}(+)$ cervical intraepithelial neoplasia 3 (CIN3) and carcinoma at FIGO IA1-IIB stages, plus normal epithelium. PB samples were obtained from women with CIN3 and stage IA cancer immediately prior to treatment; $\mathrm{PB}$ from healthy women was used as control. Subsets of PB lymphocytes were phenotyped using multicolor flow cytometry.

Results Among the differentially expressed genes identified, there were a considerable number of genes that, according to Gene Ontology, are responsible for inflammatory and innate immune responses (including interferon type I and II pathways) and belong to the system of self/non-self DNA/RNA recognition, with multiple anti-inflammatory factors found to be down-regulated, while a spectrum of interferon-stimulated genes, anti-viral/anti-microbial factors, pro-inflammatory cytokines, as well as markers of immune suppression were found up-regulated in invasive cancer. Accordingly, 'Influenza A' and 'Pyrimidine metabolism' KEGG pathways appeared to be significantly enriched. SPEED enrichment analysis revealed the TLR-, TNF alpha-, and IL1-dependent signalings among the top pathways lying behind the alterations of gene expression patterns observed at the initial stage of invasion. PPI network analysis confirmed close interrelation of differently expressed genes encoding molecular components of inflammatory response and virus recognition system. Among the circulating lymphocyte functional markers that may mirror the described immune alterations, the expression of CD161 in iNKT/NK-like T/NK cells (defined by CD3/CD56, Va24Ja18/Vb11-TCR, and CD4/CD8), the level of CD27 and delta2/delta1 ratio in Tgammadelta subpopulation (defined by CD3/TCRgd), and coexpression pattern of PD1/PDL1/LAG3/TIM3 in 4 subsets of CD4/CD8 T cells defined by the level of CD25/CD127, as well as in NK/NKT cells, were measured, and specific correlated differences between the control and cancer groups and between different lymphocyte populations were detected.

Conclusion The findings suggest deep involvement of the inflammation-associated and IC-mediated mechanisms and coordinate contribution of various $\mathrm{T}$ cell subsets with innatelike properties in initiation and promotion of invasive growth of cervical carcinoma both at local and systemic levels.

Disclosures The study was supported by the state assignment of the Ministry of Science and Higher Education, project No.0752-2020-0007 (AAAA-A20-120070290151-6). The authors declare no conflicts of interest.

\section{THE EFFECT OF OTHER HIGH-RISK HPV TYPES ON CERVICAL INTRAEPITHELIAL NEOPLASIA AND CANCER}

Seda Sahin Aker, Firat Ortaç. Ankara University Faculty of Medicine; Gynecologic Oncology

\subsection{6/ijgc-2020-ESG0.41}

Introduction/Background Cervical cancer is the most common gynecologic cancer in worldwide with an incidence of 13,1/ 100.00 and has a high mortality rate of 6,9/100.000. Highrisk human papilloma virüs (HPV) is the main cause of cervical squamous intraepithelial lesions and invasive cervical cancer. HPV 16 and HPV 18 are the most leading types in cervical cancer and cervical neoplasms. Some studies found a significant effect of other high-risk HPV types on cervical carsinogenesis some found non-significant. The effect on cervical carsinogenesis of co-infections with other high risk HPV types remains unclear. The purpose of this study is to evoluate the influence risk of cervical carsinogenesis of the other high risk HPV types.

Methodology From January 2016 to May 2020, patients who screened with cotest (pap smear and HPV DNA) and had a high risk HPV DNA positivity underwent a colposcopic analyses and biopsy enrolled the study. Patients evoluated from A Gynaecologic Oncologist or a trained fellow of Gynaecologic Oncology at department of Gynecologic Oncology of Ankara University Faculty of medicine. Patients who have a high risk HPV positivity, age between $25-65$ and non vaccinated for HPV included in the study. The exclusion criteries were pregnant paitients, age $<25$ and $>65$, treated before for cervical intraepitelial neoplasia, missing medical records, radiation therapy and total hysterectomy history.

Results Table 1 summarizes the demographic data of the patients.CIN2 + results are seen mostly at HPV 16 group ( $\mathrm{n}=60,36,4 \%)$ then respectively nonHPV $16 / 18 \quad(\mathrm{n}=40$, $24,2 \%)$, HPV 18 ( $n=36,21,8 \%)$, non $16 / 18+16 / 18(n=29$, $17,6 \%)$ group. CIN $2+$ results was found in $44,2 \%(n=73)$, $35,8 \%(n=59), 12,7 \%(n=21), 7,3 \%(n=12)$ of patients with NILM, HSIL,ASCUS and LSIL respectively. Postmenopausal status taken as a reference; a significant difference was observed in premenopausal patients $(\mathrm{OR}=2,688,95 \% \mathrm{CI}=$ 1,494-4,836 ). Gravidity and number of colposcopic biopsy

Abstract 495 Table 1

\begin{tabular}{|c|c|c|}
\hline \multicolumn{3}{|l|}{ Varisbles } \\
\hline$\hat{A F}$ & DesmtSD & $41,93 \pm 9,63$ \\
\hline \multirow[t]{2}{*}{ Gramidity } & DremesD & $193 \pm 133$ \\
\hline & Medim(Mim-Mhx.) & $2,00(0,00-8,00)$ \\
\hline \multirow{2}{*}{$\begin{array}{l}\text { Menopausal Statous, } \\
\text { (\%) }\end{array}$} & Eremenopuse & $388(74,6)$ \\
\hline & Eostmexopwase & $132(25,4)$ \\
\hline \multirow[t]{2}{*}{ Smoking $x(\% 4)$} & No & $349(67,1)$ \\
\hline & Yes & $171(329)$ \\
\hline \multirow{6}{*}{$\begin{array}{l}\text { Contraception } \\
\text { Method,n(\%) }\end{array}$} & Intronterine device & $54(10,4)$ \\
\hline & Ond contraceptives & $29(5,6)$ \\
\hline & Tubsl ligation & $19(3,7)$ \\
\hline & Condom & $73(140)$ \\
\hline & No methodusas & $334(642)$ \\
\hline & Other & $11(2,1)$ \\
\hline \multirow{2}{*}{$\begin{array}{l}\text { Sumber of } \\
\text { coboscopicbiopsy }\end{array}$} & BfemessD & $1,65 \pm 0,76$ \\
\hline & $\operatorname{Mredim}(\operatorname{Min}-\mathrm{M} h \mathrm{x})$ & $2,00(100-5,00)$ \\
\hline \multirow[t]{2}{*}{ Condsloms $n(\%)$} & Negtive & $459(883)$ \\
\hline & Positive & $61(11,7)$ \\
\hline \multirow{4}{*}{$\begin{array}{l}\text { HPV Genotype, } \\
\text { (\%) }\end{array}$} & 16 & $151(290)$ \\
\hline & 18 & $71(13.7)$ \\
\hline & Non16/18 & $228(43,8)$ \\
\hline & Nonl6/18+16/8 & $70(135)$ \\
\hline \multirow{4}{*}{$\begin{array}{l}\text { Cytology results, } \\
\text { n(\%) }\end{array}$} & HSII & $71(13,7)$ \\
\hline & LSII & $45(8.6)$ \\
\hline & ASCUS & $95(183)$ \\
\hline & NIIM & $309(59,4)$ \\
\hline \multirow[t]{5}{*}{ ECC results.n(\%) } & CIN1 & $3(1,8)$ \\
\hline & $\mathrm{CLN} 2$ & $9(5,6)$ \\
\hline & $\operatorname{cIN} 3$ & $11(69)$ \\
\hline & Corsingm & $14(8.8)$ \\
\hline & Nomal & $123(769)$ \\
\hline
\end{tabular}

